\title{
The role of epidemiology in the study of periodontal diseases
}

\author{
BRIAN A. BURT
}

Models of disease are collections of theory on its etiology and progression, based on research as far as possible but often including some untested hypotheses. As such, these models have to be modified from time to time as new research findings come out and sometimes have to be revised extensively. This is the case with the models for periodontal diseases. In fact, knowledge of the disease process has expanded so rapidly that it is easy to forget that, as recently as the mid-1960s, a widely accepted model of periodontal disease included the following:

- All gingivitis progresses to periodontitis with consequent bone loss and tooth loss.

- Virtually everyone is susceptible to periodontitis that becomes serious enough to threaten the dentition.

- The severity of periodontitis increases with age.

- Periodontal disease is the main cause of tooth loss after age 35.

By the 1990s, however, the components of this model have either been discarded or are being challenged by findings from basic, clinical and epidemiological research. In particular, the results of epidemiological research since 1980 provided a fresh look at the distribution of disease in populations and played a major role in the re-assessment of the periodontal disease models. The purpose of this chapter is to assess the contribution of epidemiological research toward the understanding of periodontal disease.

\section{Definition of epidemiology}

Epidemiology traditionally has been defined as the study of health and disease in populations, a broad definition later expanded to: "the study of the health of populations in relation to their environment and ways of living" (48). A more precise definition is: "the study of health and disease in populations, and how these states are influenced by heredity, biology, physical environment, social environment, and ways of living" (13). The science of epidemiology has made substantial contributions toward the current high level of public health in the economically developed countries. Control of nineteenth-century epidemic diseases such as cholera, scarlet fever, typhoid fever, yellow fever and tuberculosis all followed the identification of risk factors from epidemiological study, long before the advent of antibiotics. Epidemiological science evolved during the recurring epidemics of the nineteenth century, when outbreaks of fatal infectious diseases demanded remedial action at a time when the disease process itself was poorly understood. The development of epidemiology was thus driven by an urgent public health imperative. Oral epidemiology, as a branch of the parent discipline, lacked the same genesis in public health crisis, although the landmark studies that followed the identification of waterborne fluoride as the cause of "mottled enamel" (44) were driven initially by a sense of concern for public health.

Although oral epidemiology is nothing more or less than the application of epidemiological principles and methods to the study of oral conditions, its relative youth has led it to focus more on descriptive measurement than on systematic searches for risk factors. As a result, oral epidemiology to many people is synonymous with descriptive surveys, intended to measure disease experience through clinical examinations in the field. Many other studies in epidemiology, by contrast, seek to identify risk factors from data sources such as vital statistics, disease registries, hospital admissions and discharges, insurance claims, physicians' records and national survey data, all of which are now readily available to researchers through electronic data storage. The value of such databases as research resources in oral epidemiology, however, has only been discovered recently. Although oral epidemiology's roots in clinical dentistry ensure that its traditional emphasis on original data collection will always remain a high priority, the 
expense and logistic difficulties inherent in original data collection will require more reliance on databases, with their assortment of covariables, to answer certain research questions. It will also require a greater emphasis on the use of analytical techniques from the parent discipline.

\section{The nature of epidemiological study}

Epidemiology is the study of groups of people, in contrast to clinical medicine's focus on the individual patient. Group comparisons are carried out within the structure of a formal research design to identify risk factors for the condition under study. (Risk factors are characteristics associated with the onset or progression of a disease, although they are not necessarily causal factors (32).) Knowledge of risk factors can help to establish disease etiology and can also suggest control measures, even when the causal pathway for the disease remains incompletely understood. For example, the scientific basis for public policy to discourage public smoking began with the pioneering studies in the 1950s that first identified cigarette smoking as a risk factor for lung cancer (20, 21). The major risk factors for cardiovascular disease (hypertension, blood lipoprotein levels, obesity, smoking and sedentary lifestyle) were also identified through epidemiological study (16).

Knowledge of risk factors can help the clinician to identify patients at greater risk, although epidemiology cannot specify which individual patients will and will not succumb to a particular disease. Biological variation dictates that the circumstances that lead to disease in one person will not necessarily do so in another person of the same age, sex or race, even if they exhibit the same risk factors. Although the clinician implicitly understands this concept of biological variation, epidemiology seeks to determine the factors associated with a disease that are the most important in terms of its prevention and control and which correlated factors offer clues for further etiological study.

\section{Descriptive epidemiology}

Descriptive studies, or surveys, are carried out to monitor disease trends in a population. The decline in caries among children, for example, was identified by comparing results from a series of descriptive surveys conducted at different times under similar conditions $(11,65)$. The results of descriptive studies can be used to plan or evaluate programs and policies for disease control, dentist and auxiliary development and financing of dental care. Descriptive results also can stimulate the development of hypotheses for further analytical studies in epidemiological, clinical or laboratory research. National surveys on oral health in the United States, which have been carried out by both the National Center for Health Statistics and the National Institute of Dental Research, began in the early 1960 s and continue periodically (62-66). The data they collect and publish have been confined largely to caries, periodontal disease and tooth loss related to the social variables of age, gender, race and socioeconomic status. In addition to these national surveys, numerous statewide and local dental surveys have been, and continue to be, conducted.

\section{Analytical studies}

An analytical study is designed to examine the correlates of diseases and measures the effects of exposure to known or hypothesized risk factors on disease outcome (32). Analytical studies test hypotheses by measuring the strength of association between a group's disease experience with host factors, environmental exposures or behavioral variables. Cause and effect can be imputed from associations that are strong and consistent, although epidemiological study alone cannot prove etiology (48). This is true for any particular branch of research; most complete etiological models are based on information that results from epidemiological, clinical and basic research.

There are 3 types of analytical study: cross-sectional, cohort and case-control. Cross-sectional studies are usually carried out for descriptive purposes only, although their results can sometimes be analyzed for associations between disease outcome and exposure (30). In the retrospective case-control design, a group of people with the disease in question (cases) are compared with a comparable group without it (controls) for contrasts in previous exposure to hypothesized risk factors (46). Case-control studies are relatively quick and inexpensive and are an especially useful strategy to explore the etiology of uncommon conditions such as certain soft tissue lesions, temporomandibular disorders and other orofacial pain syndromes. A cohort study is a pro- 
spective design in which a group of people is observed over a period of time, during which some of the group develops the disease under study and some do not, and some are exposed to hypothesized risk factor(s) and some are not. The associations between exposure and disease outcome can then be determined (14).

The essence of analytical epidemiological studies is that they include people both with and without the disease in question and with and without the hypothesized exposure. Clinical studies, by contrast, are frequently confined to diseased or disease-susceptible people; the inclusion of large numbers of subjects does not by itself make an epidemiological study. Longitudinal observation of a group of periodontal patients, for example, may yield valuable information, but because the study group is solely patients with the disease, it is a clinical rather than an epidemiological study.

\section{Contribution of epidemiology to periodontal research}

Epidemiology can be used to describe normal biological processes such as height at various stages of growth, blood groups and times and order of tooth eruption. In the study of diseases, epidemiological study has the following 5 purposes:

\section{Understanding the natural history}

Whether to intervene or not in a disease is determined by its natural outcome. For example, most forms of cancer require intervention, but chickenpox does not.

\section{Measuring the distribution of diseases in populations}

Surveys demonstrate how diseases are distributed by age, gender, race, geographic region and socioeconomic status and can thus identify special problems.

\section{Identifying risk factors}

Even if the causal pathway of a disease is not fully understood, knowing even some of its risk factors can lead to intervention strategies for its prevention and control. The growth of smoking control measures is one example; education and regulation aimed at reducing the fat intake in the diet in the United States is another.
Testing hypotheses for the prevention and control of disease through clinical trials

Clinical trials are epidemiological experiments in which potential agents, regimens or procedures for the prevention and control of disease are tested prospectively in human populations under controlled conditions.

\section{Planning and evaluating health care services}

Data that describe a) the distribution of disease, both treated and untreated, in the population under study; b) the population's utilization of health care services; and c) the availability and productivity of health care services can assist planning for the services and personnel required. Related applications include validating the effectiveness of treatment techniques and quality assurance procedures.

Epidemiology has contributed significantly to knowledge of periodontal conditions in several of these areas. For example, poor oral hygiene was first identified as a risk factor for gingival inflammation years ago (23), and numerous clinical trials for testing treatment regimens and agents to prevent plaque accumulation have been conducted since. Probably the most interesting examples, however, are the improvement in understanding the natural history and distribution of periodontal diseases in populations. Actually, epidemiology did more than just improve understanding in these areas; it changed the very way we look at the disease.

\section{Understanding the natural history}

The principal issues in the natural history of periodontal diseases deal with the relationship between periodontitis and tooth loss and the circumstances under which gingivitis can progress to periodontitis. It was mentioned earlier that both issues were part of the conventional wisdom on periodontal diseases until recent years, a view reinforced by data such as that in Table 1, taken from the first national survey of adults in the United States in 1960-1962. In older people, relative to younger people, the proportion of edentulous people was greater, the number of remaining teeth in dentate people was lower and periodontal diseases were scored as more severe. It is easy to see how conclusions on the inevitability of periodontitis and eventual tooth loss arose from such data. 
Table 1. Number of teeth present and periodontal conditions in United States men aged 18-79 years, 1960-1962

\begin{tabular}{lcccc}
\hline $\begin{array}{l}\text { Age } \\
\text { (years) }\end{array}$ & $\begin{array}{c}\text { Percentage } \\
\text { edentulous }\end{array}$ & $\begin{array}{c}\text { No. of teeth } \\
\text { per dentate } \\
\text { Person }\end{array}$ & $\begin{array}{c}\text { Mean } \\
\text { PI }^{*}\end{array}$ & $\begin{array}{c}\text { Mean } \\
\text { OHI-S** }\end{array}$ \\
\hline $18-24$ & 1.3 & 23.2 & 0.6 & 1.5 \\
$25-34$ & 2.7 & 21.5 & 0.9 & 1.6 \\
$35-44$ & 5.9 & 19.4 & 1.3 & 1.7 \\
$45-54$ & 19.9 & 15.6 & 1.6 & 1.9 \\
$55-64$ & 34.5 & 11.4 & 2.2 & 2.1 \\
$65-74$ & 45.0 & 8.1 & 2.5 & 2.5 \\
$75-79$ & 55.7 & 4.8 & 2.9 & 2.2 \\
\hline
\end{tabular}

* Periodontal Index score (55). ** Simplified Oral Hygiene Index score (24). Source: US Public Health Service, National Center for Health Statistics (62-64).

But cross-sectional data such as those in Table 1 are often erroneously interpreted as if they were longitudinal. Doing so ignores the cohort effect, the fact that the older people represented in the data had grown up under very different conditions from those experienced by the younger ones. It is thus misleading to conclude from Table 1 that the younger people would look like the older ones when they reached the same age, but that implicit view used to be commonplace.

Study of the natural history of periodontal conditions is still complicated by tooth extractions carried out years ago. Until relatively recently, diagnoses of "pyorrhea" were made for what today would be recognized as mild degrees of periodontal involvement, and mass extraction was a common treatment. The beliefs of both dentist and patient combined with the diagnosis of "pyorrhea" to make tooth loss accepted as virtually inevitable sooner or later (67), with the result that total loss of teeth became very common among older people. The basis for this practice was the focal infection theory (28), which substantially influenced dental practice in the first half of this century. Even when faith in the focal infection theory began to fade in mid-century, reports from the 1950s and 1960s (Table 1) seemed to show that oral deposits and pocketing increased with age, as did tooth mortality, so it was natural to assume that the two were related (40). This led in turn to a circuitous logic: periodontal diseases led to tooth loss, and high levels of tooth loss showed that periodontal diseases were severe and endemic.

Even though levels of tooth retention continue to improve over more recent years, there is still a lingering problem in how to assess the progression of periodontitis with increasing age when so many older people are edentulous as a result of treatment received years before. The problem of interpreting data from surveys can be illustrated from a study in New Zealand (10), which has long had high levels of total tooth loss among older people (18). The data are shown in Table 2, together with 3 possible conclusions that can be reached from them. A second illustration of interpretive difficulty comes from a comparison of tooth loss data in the United States with that from similar age groups in Kenya, a developing country with no comparable levels of oral hygiene and dental services. In rural Kenya, $90 \%$ of people aged 15 to 60 years have retained 16 or more teeth (41), whereas only $79 \%$ of employed United States adults of similar ages had done so in 1985-1986 (66). The greater degree of tooth loss in the United States is hard to attribute to more severe periodontitis, though it is associated with more frequent and more widespread dental attendance. The natural history of the periodontal diseases is not easy to follow in a highly treated population.

Some studies have concluded that tooth retention is proportional to the degree of compliance with periodontal maintenance regimens $(6,45,68)$, but others suggest that some patients lose teeth regardless of regular maintenance care (7). A look at statistical distributions shows that most tooth loss is concentrated in a small group of patients (26). One hard-to-explain finding came from a study of patients who declined periodontal maintenance care over a 5 -year period. In this group, tooth loss was greater in teeth originally diagnosed as questionable than it was in the

Table 2. Data and conclusions from a survey of a representative sample of elderly people in Dunedin, New Zealand

Number examined:
Number edentulous:
Number dentate:
In need of:
Complex periodontal care:
Moderate periodontal care:
No periodontal care:
Source: Brown et al. (10).
Possible conclusions:
1. The data are little related to periodontal conditions;
most tooth loss could be caries-related from many
years before.
2. The data are little related to periodontal conditions;
tooth loss could stem from negative attitudes toward
their retention.
3. The data could reflect a survival phenomenon,
meaning that the periodontally diseased teeth have
been extracted and the relatively healthy teeth re-
main.


teeth diagnosed as hopeless (8). Collectively, these clinical studies suggest that periodontal maintenance care is not well correlated with tooth retention, although none challenge the hypothesis that severe disease is concentrated in a relative few people.

The old perception of periodontitis as a major cause of tooth loss was largely based on studies of dental practice records. It can now be seen, however, that these records largely reflected treatment philosophies in the early 1950s rather than a close correlation between disease progression and its outcome $(42,47,52)$. The data were seriously biased by the attitudes of the dentist and the patient and the relationship between them. More recent studies of dental practice have reported that caries, not periodontal diseases, is the principal reason for tooth extraction in all patients except perhaps the very oldest $(1,5,9,15,31)$. More than anything else, these findings probably demonstrate a change in dental treatment philosophy with respect to periodontal diseases: a recognition that many teeth involved in periodontal disease can be successfully maintained and do not need to be extracted. We can only speculate on the degree to which these research findings represent a real decrease in disease severity, improved treatment methods or more positive public attitudes toward tooth retention. The welcome end result, however, is that only the most severe and intractable periodontitis is now seen as grounds for extraction.

The earlier model of periodontal diseases assumed that gingivitis usually progressed to periodontitis unless there was active professional intervention. However, subsequent research has now shown that relatively few gingivitis sites progress to periodontitis, and the mechanism by which this progression occurs is not well understood (51). Some of the evidence for the low rate of progression of gingivitis to periodontitis has come from clinical studies in which patients with gingivitis were observed in a dental school over a period of years (37). But the most serious questioning of the earlier belief arose when epidemiological data from untreated populations in developing countries were published. Despite massive deposits of plaque and calculus (and hence extensive gingivitis), the prevalence of extensive loss of periodontal attachment in these populations was little different from that seen in industrialized countries $(2-4,19,33,38,43,50)$. If, indeed, it is usual for severe gingivitis to progress to severe loss of periodontal attachment, then these epidemiological findings become hard to explain. When they were added to the clinical evidence, it became clear that most gingivitis did not progress to severe periodontitis, even in populations that hardly practice self-care and have little access to professional treatment.

An intriguing slant on the natural history of periodontitis came with the suggestion, in the early 1980s, that diseased periodontal tissues may have the capacity to repair themselves (22). This finding became incorporated into the burst theory of periodontitis (61), which essentially states that periodontitis progresses in a series of relatively short, acute bursts of rapid tissue destruction, followed by some tissue repair and with long periods of remission (36). This view was the converse of the linear progression assumed previously. The burst theory resulted from analyzing the probing measures from individual sites, thus making site-to-site variations evident, rather than by aggregating these measures into mean data (39). The burst theory of periodontal destruction is a model many authorities have accepted (35), although the validity of statistical methods used in its early formulation has been criticized $(29,49,53)$. Modifications to the original model have also been suggested (17). Further research in time will help to confirm, refute or refine the burst theory.

\section{Measuring disease distribution}

As mentioned earlier, virtually everyone used to be considered susceptible to periodontitis. But it is now clear that data from the late 1960s that apparently showed widespread severe disease $(34,54,56,58-60)$ must be looked at skeptically because of the poor validity of the measurements at the time. In particular, the belief that virtually everyone was susceptible to advanced destructive periodontitis, especially if oral hygiene was poor, is no longer tenable. This change in perceptions might have begun with the results of a Swedish study in the early 1980s (27), which was one of the first to use a disaggregated method of measurement.

The biggest single contribution to this shift in understanding, however, was probably the outcome of a 15-year longitudinal study of 480 tea workers in Sri Lanka by Löe et al. (38). This observational study of a relatively untreated population recognized that dental treatment impeded study of the natural history of periodontitis. The tea workers, initially aged 14-30 years, were first examined in 1970. There were 5 subsequent series of examinations, the final one in 1985 when there were 161 of the original group remaining. Based on tooth loss and interproximal 
Table 3. A current model of periodontal diseases

- Few people exhibit advanced periodontal destruction. Mild gingivitis is common, as is mild-to-moderate periodontitis. Most adults exhibit some loss of probing attachment while still maintaining a functioning dentition.

- Gingivitis and periodontitis are each associated with characteristic bacterial flora that have some similarities but also some differences. Gingivitis precedes periodontitis, but relatively few sites with gingivitis later develop periodontitis.

- Although periodontitis is usually related to age in cross-sectional surveys, it is not a natural consequence of aging.

- Periodontitis is not the major cause of tooth loss in adults, except perhaps in the oldest age groups in some populations.

loss of periodontal attachment, it was concluded that about $8 \%$ of the group demonstrated rapid progression of periodontitis, $81 \%$ showed moderate progression and the remaining $11 \%$ showed no progression beyond gingivitis. In the first two groups, periodontitis progressed with age, although it progressed much more rapidly in the first group, virtually all of whom were edentulous by $40-45$ years of age. In the moderate-progression group, the annual mean loss of periodontal attachment increased from $0.3 \mathrm{~mm}$, when the members were in their twenties, to $0.5 \mathrm{~mm}$ when they were aged around 45 years. By contrast, the annual loss of periodontal attachment in the rapidly progressing group averaged $1.04 \mathrm{~mm}$ in those aged 25-29 years. In the non-progressing group, the average annual loss of periodontal attachment was about $0.05 \mathrm{~mm}$ and did not change with age. These data show that periodontitis worsened with age for the most susceptible individuals, but periodontitis in the moderate-progression group would probably not lead to tooth loss, at least until much later in life. Age did not seem to be a factor in the non-progressing group.

Confirmation that severe loss of periodontal attachment was concentrated in a minority of people was reported from other parts of the world when disaggregated measurement methods were used (12, 57). By 1988, there was sufficient evidence for a comprehensive review (25) to conclude that severe, generalized periodontitis affected about $7 \%$ to $15 \%$ of the population of any country. This is still a lot of people, and a much higher proportion exhibits a more moderate level of periodontitis, but it is a far cry from the virtually universal degree of susceptibility that had been previously assumed. Research now is focusing on what characteristics are peculiar to this susceptible minority and how they might be identified in time for preventive action to be taken.

In summary, there is still a great deal to be learned, but the accepted model of periodontal disease has changed considerably since the early 1980 s. Epidemiological research has contributed a great deal toward this revision. As a result of these studies, the current perceptions of periodontal diseases can be summarized as in Table 3. It is likely that this model will, in turn, become refined and modified as research progresses. Epidemiology, along with basic science and clinical studies, will continue to play a major role in these developments.

\section{References}

1. Ainamo J, Sarkki L, Kuhalampi ML, Palolampi L, Piirto O. The frequency of periodontal extractions in Finland. Community Dent Health 1984: 1: 165-172.

2. Baelum V, Fejerskov O, Karring T. Oral hygiene, gingivitis, and periodontal breakdown in adult Tanzanians. J Periodont Res 1986: 21: 221-232.

3. Baelum V, Fejerskov O, Manji F. Periodontal diseases in adult Kenyans. J Clin Periodontol 1988: 15: 445-452.

4. Baelum V, Wen-Min L, Fejerskov O, Xia C. Tooth mortality and periodontal conditions in 60-80-year-old Chinese. Scand J Dent Res 1988: 96: 99-107.

5. Bailit HL, Braun R, Maryniuk GA, Camp P. Is periodontal disease the primary cause of tooth extraction in adults? J Am Dent Assoc 1987: 114: 40-45.

6. Becker W, Berg L, Becker BE. Untreated periodontal disease; a longitudinal study. J Periodontol 1979: 50: 234-244.

7. Becker W, Berg L, Becker BE. The long term evaluation of periodontal treatment and maintenance in 95 patients. Int J Periodont Restorative Dent 1984: 4: 54-71.

8. Becker W, Becker BE, Berg LE. Periodontal treatment without maintenance; a retrospective study in 44 patients. J Periodontol 1984: 55: 505-509.

9. Bouma J, Schaub RMH, Poel ACM van de. Periodontal status and total tooth extraction in a medium-sized city in the Netherlands. Community Dent Oral Epidemiol 1985: 13: 323-327.

10. Brown RH, Edwards JL, Spears GFS. Periodontal and tooth treatment needs in dentate elderly people in Dunedin. NZ Dent J 1987: 83: 42-45.

11. Burt BA. Influences for change in the dental health status of populations; an historical perspective. J Public Health Dent 1978: 38: 272-288.

12. Burt BA. The pattern of periodontal destruction in industrialized countries. In: Johnson NW, ed. Markers of disease susceptibility and activity for periodontal diseases. London: Cambridge University Press, 1991: 9-26.

13. Burt BA, Eklund SA. Dentistry, dental practice, and the community. 4th edn. Philadelphia: Saunders, 1992: 52.

14. Burt BA, Eklund SA, Morgan KJ et al. The effects of sugar intake and frequency of ingestion on dental caries increment in a three-year longitudinal study. J Dent Res 1988: 67: 1422-1429. 
15. Cahen PM, Frank RM, Turlot JC. A survey of the reasons for dental extractions in France. I Dent Res 1985: 64: 1087-1093.

16. Castelli WP. Epidemiology of coronary heart disease: the Framingham study. Am J Med 1984: 76 (2A): 4-12.

17. Caton J. Periodontal diagnosis and diagnostic aids. In: Nevins M, Becker W, Kornman K, ed. Proceedings of the World Workshop in Clinical Periodontics. Chicago: American Academy of Periodontology, 1990: 11-21

18. Cutress TW, Hunter PBV, Davis PB, Beck DJ, Croxson LJ. Adult oral health and attitudes to dentistry in New Zealand 1976. Wellington, NZ: Medical Research Council, 1979

19. Cutress TW, Powell RN, Ball ME. Differing profiles of periodontal disease in two similar South Pacific island populations. Community Dent Oral Epidemiol 1982: 10: 193-203.

20. Doll R, Bradford Hill A. Lung cancer and other causes of death in relation to smoking: a second report on the mortality of British doctors. Br Med J 1956: 2: 1071-1081.

21. Doll R, Bradford Hill A. Mortality in relation to smoking: ten years of observations on British doctors. Br Med / 1964: 1: 1399-1410, 1460-1467.

22. Goodson JM, Tanner ACM. Haffajee AD, Sornberger GC, Socransky SS. Patterns of progression and regression of advanced destructive periodontal disease. J Clin Periodontol 1982: 9: 472-481.

23. Greene IC. Oral hygiene and periodontal disease. Am J Public Health 1963: 53: 913-922.

24. Greene JC. The Oral Hygiene Index: development and uses. J Periodontol 1967: 38 (part II): 625-635.

25. Griffiths GS, Wilton JM, Curtis MA et al. Detection of highrisk groups and individiduals for periodontal diseases. Clinical assessment of the periodontium. J Clin Periodontol 1988: 15: 403-410

26. Hirschfeld L, Wasserman B. A long-term survey of tooth loss in 600 treated periodontal patients. J Periodontol 1978 49: 225-237.

27. Hugoson A, Jordan T. Frequency distribution of individuals aged 20-70 years according to severity of periodontal disease. Community Dent Oral Epidemiol 1982: 10: 18 $\vec{i}-192$

28. Hunter $W$. The role of sepsis and of antisepsis in medicine. Lancet 1911: Jan 14: 79-86.

29. Imrey PB. Considerations in the statistical analysis of clinical trials in periodontitis. J Clin Periodontol 1986: 13 $517-528$.

30. Ismail AI, Burt BA, Eklund SA. Epidemiological patterns of smoking and periodontal disease in the United States. I Am Dent Assoc 1983: 106: 617-621.

31. Kay EJ, Blinkhom AS. The reasons underlying the extraction of teeth in Scotland. Br Dent J 1986: 160: 287-290.

32. Last JM, ed. A dictionary of epidemiology. 2nd edn. New York: Oxford University Press, 1988.

33. Lembariti BS, Frencken JE, Pilot T. Prevalence and severity of periodontal conditions among adults in urban and rural Morogoro, Tanzania. Community Dent Oral Epidemiol 1988: 16: 240-243.

34. Lightner LM, O'Leary TJ, Drake RB, Crump PP, Jividen GJ, Junghans JJ. The periodontal status of incoming Air Force Academy cadets. J Am Dent Assoc 1967: 75: 111-117.

35. Lindhe J, Okamoto $\mathrm{H}$, Yoneyama $\mathrm{T}$, Haffajee A, Socransky SS. Longitudinal changes in periodontal disease in untreated subjects. J Clin Periodontol 1989: 16: 662-670.

36. Listgarten MA. Pathogenesis of periodontitis. J Clin Periodontol 1986: 13: 418-430.
37. Listgarten MA, Schifter CC, Laster L. 3-year longitudinal study of the periodontal status of an adult population with gingivitis. J Clin Periodontol 1985: 12: 225-238.

38. Löe H, Anerud A, Boysen H, Morrison E. Natural history of periodontal disease in man; rapid, moderate, and no loss of attachment in Sri Lankan laborers 14 to 46 years of age. J Clin Periodontol 1986: 13: 431-440.

39. Löe H, Anerud A, Boysen H, Smith M. The natural history of periodontal disease in man: the rate of periodontal destruction before 40 years of age. J Periodontol 1978: 49: 607-620.

40. Lovdal A, Arno A, Waerhaug J. Incidence of clinical manifestation of periodontal disease in light of oral hygiene and calculus formation. J Am Dent Assoc 1958: 56: 21-33.

41. Manji F, Baelum V, Fejerskov O. Tooth mortality in an adult rural population in Kenya. J Dent Res 1988: 67: 496-500.

42. Marshall Day CD, Stephens RG, Quigley LF Jr. Periodontal disease: prevalence and incidence. J Periodontol 1955: 26: 185-203.

43. Matthesen M, Baelum V, Aarslev I, Fejerskov O. Dental health of children and adults in Guinea-Bissau, West Africa, in 1986. Community Dent Health 1990: 7: 123-133.

44. McClure FJ. Fluoridation: the search and the victory. Bethesda, MD: National Institutes of Health, 1970.

45. McFall WT Jr. Tooth loss in 100 treated patients with periodontal disease. J Periodontol 1982: 53: 539-549.

46. McGuire SM, Vanable ED, McGuire MH, Buckwalter JA Douglass $\mathrm{CW}$. Is there a link between fluoridated water and osteosarcoma? J Am Dent Assoc 1991: 122 (4): 39-45.

47. Moen D. Survey of needs for dental care. II. Dental needs according to age and sex of patients. J Am Dent Assoc 1953 : 46: $200-211$

48. Morris JN. Uses of epidemiology. 3rd edn. New York: Churchill Livingstone, 1975

49. Morrison EC, Kowalski C]. Discussion: clinical measurements of periodontitis. J Clin Periodontol 1986: 13 $456-458$.

50. Okamoto H, Yoneyama T, Lindhe J, Haffajee A, Socransky $S$. Methods of evaluating periodontal disease data in epidemiological research. J Clin Periodontol 1988: 15: 430-439.

51. Page RC. Gingivitis. J Clin Periodontol 1986: 13: 345-359.

52. Pelton WJ, Pennell EH, Druzina A. Tooth morbidity experience of adults. J Am Dent Assoc 1954: 49: 439-445.

53. Ralls SA, Cohen ME. Problems in identifying "bursts" of periodontal attachment loss. J Periodontol 1986: 57: 746-752.

54. Ramfjord SP, Emslie RD, Greene JC, Held AJ, Waerhaug J. Epidemiological studies of periodontal disease. Am J Public Health 1968: 58: 1713-1722.

55. Russell AL. A system of scoring for prevalence surveys of periodontal disease. J Dent Res 1956: 35: 350-359.

56. Russell AL. Epidemiology of periodontal disease. Int Dent J 1967: 17: 282-296.

57. Schurch E Jr, Minder CE, Lang NP, Geering AH. Periodontal conditions in a randomly selected population in Switzerland. Community Dent Oral Epidemiol 1988: 16: 181-186.

58. Sheiham A. The epidemiology of chronic periodontal disease in Western Nigerian schoolchildren. J Periodont Res 1968: 3: 257-267.

59. Sheiham A. The prevalence and severity of periodontal disease in British populations. Br Dent J 1969: 126: 115-122.

60. Sheiham A. Dental cleanliness and chronic periodontal disease: studies on populations in Britain. Br Dent $J$ 1970: 120: 413-418. 
61. Socransky SS, Haffajee AD, Goodson JM, Lindhe J. New concepts of destructive periodontal disease. J Clin Periodontol 1984: 11: 21-32.

62. US Public Health Service, National Center for Health Statistics. Selcted dental findings in adults by age, race, and sex: United States 1960-1962. Washington, DC: US Government Printing Office, 1965 (PHS Publication No. 1000, Series 11, No. 7).

63. US Public Health Service, National Center for Health Statistics. Periodontal disease in adults; United States 1960-1962. Washington, DC: US Government Printing Office, 1965 (PHS Publication No. 1000, Series 11, No. 12).

64. US Public Health Service, National Center for Health Statistics. Oral hygiene in adults; United States 1960-1962. Washington, DC: US Government Printing Office, 1965 (PHS Publication No. 1000, Series 11, No. 16).
65. US Public Health Service, National Institute of Dental Research. The prevalence of dental caries in United States children 1979-80. Washington, DC: US Government Printing Office, 1965 (NIH Publication No. 82-2245).

66. US Public Health Service, National Institute of Dental Research. Oral health of United States adults; national findings. Washington, DC: US Government Printing Office, 1987 (NIH Publication No. 87-2868).

67. Weintraub JA, Burt BA. Tooth loss in the United States. J Dent Educ 1985: 49: 368-376.

68. Wilson TG Jr, Glover ME, Malik AK, Schoen JA, Dorsett D. Tooth loss in maintenance patients in a private periodontal practice. J Periodontol 1987: 58: 231-235. 